\title{
FULMINANT HEPATITIS SECUNDARY TO CYCLOPHOSPHAMIDE IN THE TREATMENT OF SYSTEMIC LUPUS ERYTHEMATOSUS
}

\author{
Flavio Barboza ${ }^{1, \star}$, João Pedro Mendes Neto ${ }^{1}$, Renan Pagliaminuta e Silva ${ }^{1}$, Rafael Garcia de Maria ${ }^{1}$ \\ 1.Universidade Federal de Mato Grosso, Sinop (MT), Brazil. \\ ${ }^{\star}$ Corresponding author: flavio.fbarboza@uol.com.br
}

\section{BACKGROUND}

Cyclophosphamide is an alkylating agent frequently used in treatment of hematologic diseases and autoimmune rheumatologic disorders, usually applied to major severity cases, such as lupus nephritis. The medication is an inactive prodrug and is activated by cytochrome P450 to form active metabolites such as 4-hydroxycyclophosphamide, acrolein and phosphoramide mustard. Despite its therapeutic action, these metabolites can cause bone marrow aplasia and liver toxicity. The hepatic changes can be: mild transaminases disorder, acute cholestatic hepatitis and fulminant hepatitis. The latter can lead to death if not recognized and urgently referred to liver transplant.

\section{CASE REPORT}

Female, 21 years old, diagnosed with systemic lupus erythematosus (fever, arthritis, oral ulcers, leukopenia, lymphopenia, C3 and C4 hypocomplementemia, 1/640 ANA speckled pattern, positive anti-DNA and IgG anticardiolipin in high titles). After one year of remission in use of methotrexate, hydroxychloroquine and aspirin, the patient presented with anasarca, weakness and asthenia. The requested exams revealed: albumin: $2.6 \mathrm{~g} / \mathrm{dL}$, hemoglobin: $9.7 \mathrm{~g} / \mathrm{dL} ; \mathrm{C} 3$ and $\mathrm{C} 4$ hypocomplementemia, high anti-dsDNA levels, creatinine: $0.95 \mathrm{mg} / \mathrm{dL}$, urea: $30 \mathrm{mg} / \mathrm{dL} ; 24$ hours urinary protein: $6700 \mathrm{mg}$, urinalysis with erythrocyte dimorphism and leukocyturia, TGP: $15 \mathrm{U} / \mathrm{L}$ and TGO: $15 \mathrm{U} / \mathrm{L}$. Afterwards diagnosis assumed as class 4 lupus nephritis, the patient was admitted for clinical condition stabilization and was made methylprednisolone, at $1 \mathrm{~g} /$ day for 3 days, after infectious causes have been discarded and in the fourth day, cyclophosphamide (CFM) $1 \mathrm{~g}$ was administered (body surface $=1.6 \mathrm{~m}^{2}-0.75 \mathrm{~g} / \mathrm{m}^{2}$ ). Clinical conditions evolved $24 \mathrm{~h}$ from CFM to diffuse abdominal pain, jaundice, nausea and vomit. Physical exams indicated scleral icterus, large hepatomegaly and low blood pressure levels $(70 \times 40 \mathrm{mmHg})$. Additional exams revealed increased bilirubin, alkaline phosphatase and gamma-glutamyl transferase, TGP: 5113.0 U/L, TGO: 3543.0 U/L, TAP enlargement (RNI: 4.7) and negative hemocultures. The patient was diagnosed with fulminant cholestatic hepatitis and has been referred to an intensive treatment unit. The patient was listed to emergent liver transplant, but the hemodynamic instability associated with disseminated intravascular coagulation progressed. After 5 days in intensive care, she died, before the liver transplant could be performed.

\section{CONCLUSION}

Cyclophosphamide is widely used in rheumatology to induce the treatment of severe cases. However, despite their correct recommendation, the drugs applied in the treatment of lupus nephritis can cause intense side effects. Therefore, the rheumatologist must be aware of the early manifestations of nausea and vomiting. Acute liver failure can occur fulminantly with high mortality rate if urgent liver transplantation is not accomplished.

\section{KEYWORDS}

Cyclophosphamide, Systemic lupus erythematosus, Fulminant hepatitis. 